SCIREA Journal of Clinical Medicine

ISSN: 2706-8870

http://www.scirea.org/journal/CM

November 16, 2021

SCIREA

Volume 6, Issue 6, December 2021

\title{
The quality of life, anxiety, and depression in adults with mild intellectual disability during lockdown due to COVID-19 pandemic in Greece
}

Ioannis Paxinos*,PhD., University of Nicosia, Adjunct faculty position, Child Hospital P\&A Kyriakou, Athens, Greece

Dimitra Chaldi, PhD. Student, M.ADS, BSc. S-LP, Speech \& Language Pathologist at "Speech Rehabilitation Institute", Patra, Greece

Natalia Paxinou, MSc. in Stress Management and Health Promotion

Email: ioannispaxinos@yahoo.com

\section{Abstract \\ Objective}

The quality of life experiences of people with intellectual disability during the lockdown due to the COVID-19 pandemic have received less attention in outcome research in Greece. The aim of this study was to investigate the perceived Quality of life perceptions, anxiety and depression, of individuals with a mild intellectual disability.

\section{Method}

A sample of 101 individuals aged from 18-25 who had previously been diagnosed by child psychiatric services as having a mild intellectual disability participated in this cross-sectional study examining the impact of lockdown during the COVID-19 pandemic on the well-being of 
clients of psychiatric services. The relationship between variables of interest and participants' demographic characteristics was also analyzed.

\section{Results}

Results showed that our sample reported moderate levels of quality of life, while expressing higher levels in the subscale of satisfaction and low levels of Independence. The employees of our sample referred higher satisfaction levels in comparison with the unemployed participants. We found also rather higher levels of anxiety and depression.

\section{Conclusion}

Results provide evidence that individuals with intellectual disabilities are able to give valid responses concerning the manner that they perceive their lives. Creation of basic data for further research is a future aim in case of a new outbreak. The future purpose is to create a database for further research in case of a new pandemic.

Keywords: quality of life, stress, depression, intellectual disability, COVID-19 pandemic

\section{Introduction}

According to the "Dictionary of the Modern Greek Language", the word pandemic appeared in 1892 from the Neo-Latin pandemia and means "an epidemic that spreads throughout a country or region, affecting the entire population". Both recent and ongoing studies have documented the burden on people's mental health due to the Covid-19 pandemic ${ }^{1,2}$. According to Galea ${ }^{3}$, social isolation and confinement, due to Covid -19 , has caused a significant increase in the stress and depression rates of a large portion of our fellow human beings. Research data during isolation ${ }^{4}$ showed a number of emotional disorders such as stress, depression, insomnia, fear, irritability, anger, and confusion. Individuals with intellectual disability (ID) appear to be particularly vulnerable to the physical and social psychological impact of pandemic. Sudden life changes and imposed social constraints can cause them to increase levels of anxiety, depression, and stress by over focusing on the volume of information about the present disease and thus reducing the maintenance of their social behavior ${ }^{5}$. 
Although the concept of Quality of Life was first mentioned by United Stated President Johnson in his 1964 campaign speech, it came to the fore during the 1980s and has since been widely used as a scientific concept, causing an "explosion" with applications in various fields. Quality of life is considered particularly important among others in health, education, and social services aiming at a) individualized interventions at the level of the microsystem ${ }^{6}, \mathrm{~b}$ ) the creation of strategies to improve the quality of life at the level of the macrosystem ${ }^{7}$, and c) in the exercise and implementation of social policies ${ }^{8}$.

The universality and heterogeneity of the use of the term creates enormous difficulties for a commonly accepted definition. The concept is multidimensional, contains semantic polysemy and conceptual ambiguity, and is additionally defined differently from the various research fields (e.g., psychology, sociology, etc.) making its clarification a particularly difficult case. $\mathrm{Liu}^{9}$ characteristically stated that "there are as many definitions of quality of life (QoL) as there are people". The lack of agreement of a commonly accepted definition and the necessary tools for measuring it, led to many different interpretations, depending solely on the theoretical background of each researcher. Nowadays it is generally used to describe a variety of objective and psychosocial variables, including health status, functional behavior, symptomatology, perceptions, happiness, etc. Although in the field of research, several objective indicators are used such as physical health, functional ability, psychological well-being, financial situation. These indicators, alone, cannot provide a clear picture of quality of life without being accompanied by subjective assessments and personal values of individuals themselves, while the interaction between objective and subjective variables is under discussion ${ }^{10,11,12 \text {. }}$

Shalock ${ }^{13}$ states that this is a social construction since every society aims to improve and elevate the quality of life of people. Although there is universal agreement on the need for quality of life measurements, very little research has looked at how governments promote these findings to improve the lives of their citizens ${ }^{14}$. According to the World Health Organization ${ }^{15}$ (WHO) (1993) "quality of life is the subjective perception of individuals about their place in life, within the cultural contexts and value systems of society that live according to their goals, expectations, standards and concerns".

The evolution of the concept of "Quality of Life" reflects the shift from a paternalistic conception to the evaluation of the individual, to the growing interest in respect, autonomy, and the subjective experience of each person ${ }^{16}$. Recently, the term has been increasingly used 
for person-centered planning as a key condition for implementing policies and services, as an indicator for evaluating the results of therapeutic interventions, and as a model for exploring the impact of individual and environmental factors on people's assessments of their lives ${ }^{17}$.

Barry ${ }^{18}$ believes that people's perceptions of their lives are influenced by the interaction of several factors, such as individual and clinical characteristics, psychological concepts, personal values and beliefs, objective conditions and various cognitive mechanisms that ultimately mediate and shape similar perceptions. Schalock \& Verdugo ${ }^{17}$ state eight factors that mediate quality of life perceptions, which are the following: 1) personal development, 2) emotional wellness, 3) self-management, 4) interpersonal relationships, 5) social inclusion, 6) rights,7) physical health, and 8) material well-being.

Verdugo $^{19}$ emphasizes that quality of life assessment should be based on three statutory principles: 1) it is important for all people and should be approached in exactly the same way for everyone, including people with intellectual disabilities, 2) evaluation should focus on how people experience their lives and personal well-being, and 3) quality of life evaluation reflects a mixture of two different meanings, something that is generally accepted and understood by all people and something that is meaningful to them about their lives, giving a personal interpretation to their experience. It follows that there is a need for a constant dialogue with the individual ${ }^{20}$ and in this process of assessing the quality of life no individual can be excluded despite the presence of cognitive deficits ${ }^{21}$.

In most surveys, the term quality of life is used to describe respondents' personal perceptions of their lives. In this way it can be used for relevant - but essentially very different concepts ending up with what is assessed not to be actually quality of life ${ }^{22}$. Concepts are often used as synonyms, such as "health state" or "health related quality of life", which are multidimensional, broad and include physical, psychological and social components of life, but are not related with the individual perception of the individual about his life, values, and expectations. People with exactly the same condition (i.e., health condition) may make completely different assessments of their quality of life. Emphasis should be placed on the uniqueness of the individual, as the expectations and personal meaning of each person can modify objective situations into subjective values and interpretations ${ }^{23}$. Wrong choice of measuring tool can have negative consequences on the assessments of the quality of life perceptions of the respondents ${ }^{22}$. 
In the past, the perceptions of quality of life of people with ID were evaluated either through third parties or on the basis of some social indicators (e.g., health, social relations, safety). As perceptions have changed in recent decades, both in terms of ID and approaches to quality of life assessment, it is considered essential that people with ID can be actively involved in their life assessment processes ${ }^{19}$. Another research $^{24}$ recorded high correlations between assessments of the quality of life of people with ID as well as their relatives and careers.

ID is the most studied but also the most heterogeneous group both in terms of etiology and in terms of social adjustment. Studying the path of relevant terminology, one encounters terms such as mental disability, mental retardation (delay), and severe learning difficulties ${ }^{25}$. The change in the terms used from time to time shows the connection of the community with the phenomenon, so any change in its conditions is reflected in the evolution of terminology ${ }^{26}$. In the United States of America (USA) the former term mental retardation has been replaced by the term "intellectual disability" reflecting the shift to an ecological approach that focuses on the environment and its interaction with the individual, recognizing the importance of individualized educational programs, "while in United Kingdom this change has been relatively silent" ${ }^{27}$. ID is considered as something more than a biomedical condition or a psychoeducational deficit. It should be understood as a social construction and defined as a lack of social adjustment and absence of expected social behavior ${ }^{28}$. It is characterized by significant deficits in both the intellectual and adaptive functions of the individual and is expressed on a mental, social and practical level starting during the developmental period. These deficits reflect a) a significant weakness or limitation both in the individual's functional capacity and in the achievement of social roles and tasks b) it concerns a substantial disability of the individual c) it can be influenced by many factors and d) these deficits can be reduced through effective interventions and support ${ }^{29}$.

Nowadays, it is necessary to redefine the relationship between "normality" and "irregularity". A new orientation and a new approach is necessary, giving more focus to the capabilities of the same person, to the environment in which he lives and works as well as to his functional level. It is no coincidence that in recent years the research interest has focused more on the failure of modern society to deconstruct the social construct "mental retardation", to provide adequate education and adequate support to these individuals instead of focusing on the weaknesses of individuals themselves. 
Contradictory findings appear in the international literature regarding the relationship between quality of life in people with ID and typically developing individuals. Other researchers believe that the quality of life of people with ID is lower than that of normal developing individuals ${ }^{30,31}$, while other research confirms these results only in the areas of emotional wellbeing, health and productivity ${ }^{32}$, interpersonal relationships, social inclusion, self-management, rights $^{33}$. Variables that are believed to have a significant influence on Quality of life are: housing, intensity of support, living conditions, safety, employment, social skills, and satisfaction of social contacts.

\section{General Characteristics of the research}

The present study aims to investigate the perceptions of Quality of Life, anxiety, and depression of people with mild mental retardation during incarceration due to the pandemic. More specifically, the research questions concern the existence of any correlations between the variables of interest and demographic variables, as well as between the overall quality of life and the other questionnaires.

As for the general reflection and its philosophy, our research is part of the scientific field that is mainly described by Clinical Psychology.

The evaluation of perceptions of quality of life, stress, and depression was based on the Negotiation model, the creation of a "partnership" with the family of people with mild mental retardation to facilitate both the identification of these perceptions and their active participation in the process evaluation. The research process applied in our research focused on the Exploratory-descriptive strategy by examining these perceptions in a series of variables as they are described and presented in the international literature.

\section{Aims of the study}

A cross-sectional correlation research design was used to conduct the study. The purpose of this study was to describe and examine the outcomes for a number of individuals with a mild intellectual disability in terms of quality of life, anxiety, and depression during the lockdown due Covid-19.

In addition, the relationship between individuals perceived quality of life and subjective reporting anxiety, depression and impact of everyday life, was explored. 


\section{Method}

\section{A. Sample selection}

As part of the research, the perceptions of quality of life, anxiety and depression of individuals who had previously been diagnosed with mild intellectual disability by the Child Psychiatric Department services in Greece, during lockdown due COVID-19 pandemic, were investigated.

\section{B. Procedure of data collections and data analysis}

Each participant and his family, was contacted to ensure his participation in the research. After signing a written informed consent form to indicate voluntary participation in the study, persons were asked to complete the scales. Data were collected by using The Quality of Life Questionnaire, Beck's BDI Depression Inventory, The Spileberg State-Trait Anxiety and an improvised questionnaire. All individuals resided with their parents, and it was ensured that none of the participants now had any serious physical or mental difficulties and that all individuals were adults.

Eleven people had a part time job (e.g., brochure distributors, a family business and a fourhour job in a supermarket) with the assistance of either the hospital social service or other agencies (e.g., church). The selection of the sample was made based on the records of the Regular Outpatient Clinics of the child psychiatric department and the availability and response of the individuals themselves.

A total of 110 questionnaires were sent but 9 were not included in the analysis due to insufficient completion (response rate 92.6\%). Initially, there was a telephone communication with the parents of the children, where their consent to the research was requested and then both the parents of the children and the individuals themselves were thoroughly informed about the research purposes via Skype.

The questionnaires were sent to the parents of the sample by email after consultation in the period from March 22 to April 23, 2021. Out of 101 people, 7 people completed the questionnaires with the help of parents. Individuals were not treated as mere sources of information, but an attempt was made to integrate them vigorously into the research process.

\section{Research design}

This study utilized a descriptive and correlation research design. The objective was to examine the perceived quality of life, anxiety and depression of people with mild intellectual disability 
during the period of isolation because of covid-19. In this study, research tools and data analysis have come out from research instruments adapted in the Greek situation.

\section{Research instruments and data analyses}

Data presented in this study have come out from research instruments adapted in the Greek situation. The instruments which were applied are defined below:

The Quality of Life Questionnaire by Schalock and Keith (1993) ${ }^{34}$ which is has been designed for people with intellectual disabilities. It includes 40 questions and reviews four different scales 1) satisfaction (i.e., a general assessment of their life), 2) adequacy/productivity (i.e., satisfaction with the benefits of their work) 3) empowerment/independence (i.e., degree of decision making), and 4) social inclusion which is rated by 1 (unsatisfied) to 3 (slightly satisfied). According to the researchers, the scale is not considered suitable for people under the age of 18. The questionnaire has been translated and weighted in Greek.

Beck's BDI Depression Inventory ${ }^{35}$. The questionnaire consists of 21 structured questions presented in the form of multiple choice. Each question includes a series of four selfassessment answers, which relate to the intensity level of the symptom and are scored with 0 (minimum intensity), 1,2 and 3 (maximum intensity). Score 20 means that there is a very mild depression, less than 30 mild depression, less than 40 moderate depression, and more than 40 severe depression. The value 21 is considered as a threshold value for clinical cases. The questionnaire has been translated and weighted in Greek.

The Spileberg State-Trait Anxiety ${ }^{36}$. The questionnaire consists of two scales on a total of 40 questions and separates stress as a personality trait (A-trait) by investigating how the person generally feels from stress as a state (A-state) by assessing the psychological state of the person at that time. The answers to the questions are given on a Likert scale. The total value of the scale ranges between 20 -60 where higher values indicate a higher level of state anxiety.

An improvised questionnaire which concerned the impact of the pandemic on the daily life of the sample and consisted of 15 questions. More specifically, the following variables were examined: effect on health (six questions), change of his daily habits (six questions) and the use of digital media (three questions). The answers were evaluated on a four-point Likert scale $(1=$ Does not fit at all, $2=$ Does not fit, $3=$ Fits, $4=$ Fits well). From the history records of 
people who had previously been diagnosed with a mild mental disability, we collected information on demographics such as IQ, educational level, age, first visit to the outpatient clinics of the child psychiatric ward, place of origin etc.

\section{E. Statistical analyses}

SPSS 24.0 statistical package was used for the analyses. Analysis of the quality of life was carried out on the subjective composite indices for each life domain. Normality was tested with the Kolmogorov-Smirnov test.

The composite indices were compiled by summing the score of the individual items in each life area. Composite scores were also calculated for the STAIC and BDI. The internal reliability of the above scales was examined.

The overall reliability coefficient of QoL-Q is quite high Cronbach $a=0.85$ indicating the internal coherence of the questionnaire, satisfaction $\mathrm{a}=0.81$, =Adequacy/Productivity $\mathrm{a}=86$, Empowerment/Independence $a=69$, Social Inclusion /Integration $a=74$. For STAIT $(a=0.93)$, for TRAIT $(\mathrm{a}==0.87)$ and BDI $(\mathrm{a}=0.94)$, were high, showing internal consistency reliability of the scales. Statistical analyses were performed with the use of the Independent T-Test and One Way ANOVA in order to investigate differences between male and female individuals, less educated versus more educated. To control the relationship between two quantitative variables we used the Pearson correlation coefficient $r$. A p value 0.05 was considered to signify statistical significances.

\section{Results}

\section{Profile of sample: demographic characteristics}

The sample consists of 101 individuals (mean age 21.7 and range 18-25), 66 men and 35 women who were previously monitored from 2010 to 2020 in the Child Psychiatric Department of Services for evaluation, support and integration into rehabilitation programs.

All individuals had previously been evaluated with WISC III, diagnostic tool, and were diagnosed with mild mental retardation (50-69) with an average IQ of 62. All individuals in the sample attended general primary and secondary schools, attending integration classes or 
parallel support, while the majority of the sample were graduates mainly of private Lyceums $\mathrm{N}$ $=85(84.1 \%)$ and sixteen High School graduates (15.9\%).

First, we will present the descriptive statistics (mean and standard deviation) and then will are followed the correlation between the above scales.

Table 1. Sociodemographic Characteristics of the Sample

\begin{tabular}{|l|c|c|}
\hline & $\begin{array}{r}\text { Males } \\
(\mathrm{N}=66, \\
65.3 \%)\end{array}$ & $\begin{array}{c}\text { Females } \\
(\mathrm{N}=35,34.7 \%)\end{array}$ \\
\hline Age & & \\
\hline $18-22 \mathrm{~N}=86(85.1 \%)$ & $54(82 \%)$ & $26(74.3 \%)$ \\
\hline $23-25 \mathrm{~N}=15(14.9 \%)$ & $12(18 \%)$ & $9(25.7 \%)$ \\
\hline Educational level & & \\
\hline Secondary education $\mathrm{N}=72(85.2 \%)$ & $45(62.5 \%)$ & $27(37.5 \%)$ \\
\hline Up to primary education $\mathrm{N}=19(14.8)$ & $11(57.9 \%)$ & $8(42.1 \%)$ \\
\hline Occupational Status & & \\
\hline Non employees $\mathrm{N}=89(88.1 \%)$ & $59(89.4 \%)$ & $31(88.6 \%)$ \\
\hline Part-time employees $\mathrm{N}=12(11.9 \%)$ & $7(10.6 \%)$ & $4(11.4 \%)$ \\
\hline
\end{tabular}

\section{Quality of life-Q}

In terms of quality of life assessments (Table 2), the highest value is recorded in satisfaction (22.2), followed by the variables of adequacy / productivity (20.4), social inclusion (20.3) and empowerment / independence (18.6). Only two respondents have a higher score of 101 and therefore no conclusion can be drawn that indicates the trend of the sample. The range of common responses in the sample of overall quality of life ranges from 63-101. In the sub-scale "Satisfaction" $65.3 \%$ of respondents state "that their life has been treated like everyone else", $53.6 \%$ "takes some joy and fun from life", 50.4\% compared to others I am about the same condition ", 58.8\% report that they feel lonely at least 5-6 times a month while $47.6 \%$ state that "they have the same number of problems as the others".

In the Adequacy / Productivity scale, 53.7\% feel "good at the job they do", $62.2 \%$ do not know what the right skills are for a better job, $95.1 \%$ feel that they are not paid according to their job and $96.1 \%$ does not earn enough to buy goods that it needs ". 
In the Empowerment / Independence subscale $66.8 \%$ have partial control of their daily life (sleep, diet, etc.) $37.6 \%$ decide how they will spend their money, while $52.8 \%$ say that friends can visit it after approval someone. Additionally, 52.3\% reported that people who live with them quite often offend, upset or frustrate them emotionally.

Finally, regarding the subscale Social Inclusion / Integration, 43.4\% report that they receive visits from friends at home, only $29.3 \%$ associate with neighbors, $68 \%$ believe that "their life is okay" and "their neighbors behave fairly $59.3 \%$ and they feel anxious with what they are asked $(51,1 \%)$.

In the depression scale (Table 2), the presence of mild depression is observed (M.O 21.7 BDI> 20). More specifically, a percentage of $62.3 \%$ for women and $59.3 \%$ for men showed higher values described as pathological (BDI> 10). In the classification of depressive symptoms, $32.7 \%$ of the sample $(\mathrm{N}=33)$ appears to present mild mood disturbance and borderline clinical depression (11-20 BDI) to moderate (21-30 BDI) based on the symptoms.

Regarding the existence of stress, high percentages are recorded with the average stress as a condition $(\mathrm{M}=40.8)$ being higher than stress as a personality trait $(\mathrm{M}=38.1)$ In the Improvised Questionnaire on the effects of the pandemic, 68.3\% reported that the isolation caused severe anxiety, $71.7 \%$ worried that he might be affected, $54 \%$ went to bed after $01.00,37 \%$ reported feeling lonely $56 \%$ did not go out on a daily basis at home, $66.2 \%$ felt sad and anxious, while $87 \%$ reported using various digital media for more than 8 hours a day.

Table 2. Means and Standard Deviations, on various subscale

\begin{tabular}{|l|c|c|}
\hline Variables & Mean, SD & Range \\
\hline QOL-Q min-max 4-120 & & $15-27$ \\
\hline Satisfaction (1-30) & $22.2(2.4)$ & $11-27$ \\
\hline Adequacy/Productivity & $20.4(3.9)$ & $12-28$ \\
\hline $\begin{array}{l}\text { Empowerment/ } \\
\text { Independence }\end{array}$ & $18.6(4.1)$ & $17-26$ \\
\hline Social Inclusion /Integration & $20.3(2.9)$ & $63-101$ \\
\hline Total QoL & $81.5(7.6)$ & $7-30$ \\
\hline BDI min-max 0-62 & $21.7(3.1)$ & $26-56$ \\
\hline STAIC-S min-max 20-60 & $40.8(2.2)$ & \\
\hline
\end{tabular}




\begin{tabular}{|l|c|c|}
\hline STAIC-T min-max 20-60 & $38.1(3.4)$ & $24-51$ \\
\hline Improvised Questionnaire & & $14-21$ \\
\hline Changes in daily life & $19.2(1.2)$ & $13-22$ \\
\hline Health impact & $18.4(1.9)$ & $5-12$ \\
\hline Use of Digital1-12 & $9.1(2.4)$ & \\
\hline
\end{tabular}

\section{Relationships of quality of life to the other variables}

We wanted to investigate the relationship between the subjective indices of Quality of Life with depression, anxiety, health impact, changes in daily life, use of digital.

There is a systematic significant negative correlation between subjective indices and depression, anxiety ranging from moderate to high Table 3. High correlation is observed between satisfaction and depression $(r=-.74)$, state anxiety $(r=-.72)$, trait anxiety $(r=-70)$, change in daily life ( $r=-67)$, health impact $(r=-62)$.

Table 3 shows also the high positive correlations between Overall Quality of Life and the Empowerment / Independence subscales $r=.71$, Social Inclusion / Integration $r=.70$ Adequacy / Productivity $r=.68$, and less with Satisfaction $r=.44$ and Empowerment / Independence $r=.43$. Correlation is recorded between Satisfaction and Empowerment / Independence, Social Inclusion / Independence $r=.43$ and Adequacy / Productivity $r=.42$.

It seems that each subscale separately shows a statistical significant correlation with the Total quality of life, which shows the total estimate of quality of life of individuals with intellectual disabilites. 
Table3. Pearson $r$ correlations between the subjective indices of quality of life with the other variables

\begin{tabular}{|c|c|c|c|c|c|c|c|c|c|c|c|}
\hline & $\begin{array}{l}\text { Total } \\
\text { QoL }\end{array}$ & $\begin{array}{l}\text { Satisfac } \\
\text { tion }\end{array}$ & $\begin{array}{c}\text { Adequacy/ } \\
\text { Productivity }\end{array}$ & $\begin{array}{l}\text { Empowerment/ } \\
\text { Independence }\end{array}$ & $\begin{array}{c}\text { Social Inclusion } \\
\text { /Integration }\end{array}$ & $\begin{array}{c}\text { State } \\
\text { Anxiety }\end{array}$ & $\begin{array}{c}\text { Trait } \\
\text { Anxiety }\end{array}$ & $\begin{array}{c}\text { Depres } \\
\text { sion }\end{array}$ & $\begin{array}{c}\text { Changes in } \\
\text { daily life }\end{array}$ & $\begin{array}{l}\text { Health } \\
\text { impact }\end{array}$ & $\begin{array}{l}\text { Use of } \\
\text { digital }\end{array}$ \\
\hline Total QoL & - & $.47^{*}$ & $.68^{* *}$ & $.71^{* *}$ & $.70 * *$ & $-.54 * *$ & $-.53 * *$ & $-.59 * *$ & $-.56^{* *}$ & $.44^{*}$ & $-57 * *$ \\
\hline Satisfaction & - & - & $.42 *$ & Ns & Ns & $-.72 * *$ & $-.70 * *$ & $-.74 * *$ & $-.67 *$ & $-.62 * *$ & $.71^{* *}$ \\
\hline $\begin{array}{l}\text { Adequacy/Produ } \\
\text { ctivity }\end{array}$ & - & - & - & Ns & Ns & $-.54 * *$ & $-.56^{* *}$ & $-73 * *$ & $-68 * *$ & $-.64 * *$ & $-.63 * *$ \\
\hline $\begin{array}{l}\text { Empowerment/ } \\
\text { Independence }\end{array}$ & - & - & - & - & $.43^{*}$ & $-68 * *$ & $-.62 * *$ & $-.70 * *$ & $-.66^{* *}$ & $-.71 * *$ & $-.74^{* *}$ \\
\hline $\begin{array}{l}\text { Social Inclusion } \\
\text { /Integration }\end{array}$ & - & - & - & - & - & $-.70 * *$ & $-.63^{* *}$ & $-.69 * *$ & $-.71 * *$ & $-58 * *$ & $-72 * *$ \\
\hline State Anxiety & - & - & - & - & - & - & $.72 * *$ & $.52 * *$ & $73 * *$ & $-69 * *$ & $.57 * *$ \\
\hline Trait Anxiety & - & - & - & & - & - & - & $.63^{* *}$ & $69 * *$ & $.58^{* *}$ & $.62 * *$ \\
\hline Depression & - & - & - & - & - & - & - & - & $.73^{* *}$ & $.70 * *$ & $.57 * *$ \\
\hline $\begin{array}{l}\text { Changes in daily } \\
\text { life }\end{array}$ & - & - & - & - & - & - & - & - & - & $.73 * *$ & Ns \\
\hline Health impact & - & - & - & - & - & - & - & - & - & - & - \\
\hline Use of digital & - & - & - & - & - & - & - & - & - & - & - \\
\hline
\end{tabular}

$* \mathrm{p}=0.05, * * \mathrm{p}=0.01, \mathrm{~ns}=$ not significance 
The relationship between quality of life dimensions and demographic variables such as gender, age, IQ, educational level and occupational status of the sample was investigated. Investigating gender differences, male persons satisfaction scores were significantly higher compared to females $\mathrm{t}(103)=12.54=\mathrm{p}<.05$ (Table 5).

In addition no significantly differences were found in the other variables of QoL-Q. Concerning the existence in the State and Trait Anxiety scale, statistically significant differences were found between males and females. Specifically, females reported higher levels of anxiety than males $\mathrm{t}(96)=8.65=\mathrm{p}<.001$, and $\mathrm{t}(96)=7.51=. \mathrm{p}<.001$. We can see also that males scored lower in BDI scale in comparison with females, $\mathrm{t}(37)=-2.48=\mathrm{p}<.001$.

Table 5. Means and Standard Deviations on various subscales regarding Gender Differences Males $\mathrm{N}=66$ Females N=35

\begin{tabular}{|ll|c|c|}
\hline \multicolumn{2}{|c|}{ Mean (SD) } & Mean (SD) & P \\
\hline QOL-Q & 24.4 & & $.02^{*}$ \\
\hline Satisfaction & 21.6 & $22.3(2.76)$ & NS** \\
\hline Adequacy/Productivity & 18.3 & $18.8(2.68)$ & NS ** \\
\hline $\begin{array}{l}\text { Empowerment/ } \\
\text { Independence }\end{array}$ & 19.2 & $20.7(5.21)$ & NS $^{* *}$ \\
\hline Social Inclusion /Integration & $83.5(5.3)$ & $82(6.5)$ & NS $^{* *}$ \\
\hline Total QoL & 37.1 & 41.9 & $.001^{*}$ \\
\hline State Anxiety & 34.6 & $39.8 .87(2.62)$ & $.001^{*}$ \\
\hline Trait Anxiety & 18.1 & $22.9(4.11)$ & $.001^{*}$ \\
\hline BDI & & \\
\hline $\begin{array}{l}\text { Independent Samples } t \text {-test }{ }^{*} p<0.05, N=101 \\
* * N S=N o t \text { significant }\end{array}$ & & \\
\hline
\end{tabular}


Table 6. Means and Standard Deviations, on various subscales regarding Group Differences in Education

\begin{tabular}{|l|c|c|c|}
\hline & $\begin{array}{c}<9 \\
\mathrm{~N}=19\end{array}$ & $\begin{array}{c}>9 \\
\mathrm{~N}=72\end{array}$ & $\mathrm{P}$ \\
\hline QOL-Q & & & $.001^{*}$ \\
\hline Satisfaction & 21.5 & 24.9 & $\mathrm{NS} * *$ \\
\hline Adequacy/Productivity & 20.1 & 19.4 & $\mathrm{NS} * *$ \\
\hline $\begin{array}{l}\text { Empowerment/ } \\
\text { Independence }\end{array}$ & 18.2 & 18.4 & $\mathrm{NS} * *$ \\
\hline Social Inclusion /Integration & 17.3 & 84.4 & $.001^{*}$ \\
\hline Total QoL & 77.1 & 39.2 & $\mathrm{NS} * *$ \\
\hline State Anxiety & 38.6 & 36.9 & $\mathrm{NS} * *$ \\
\hline Trait Anxiety & 36.7 & 21.7 & NS** \\
\hline BDI & 20.5 & & \\
\hline
\end{tabular}

Independent Samples t-test ${ }^{*} p<0.05, N=101 * * N S=$ Not significant

Regarding education, more educated persons presented higher levels of satisfaction and total Quality of Life, $\mathrm{t}(45)=2.72=\mathrm{p}<.01$, and $\mathrm{t}(41)=2.76=. \mathrm{p}<.001$ while no differences found between anxiety and depression between them.

\section{Correlation between satisfaction with occupational status}

The correlation between satisfaction and occupational status of the sample was studied using the Mann-Whitney U criteria. As we can observe in Table 7, part-time employees expressing greater satisfaction than non-employees $U=317.5, p<0.01$. 
Table 7. Correlation between occupational status and satisfaction

\begin{tabular}{|l|c|c|c|l|l|}
\hline Occupational status & $N=101$ & Mean (SD) & $U=317.5$ & & \\
\hline Part-time Employees & 12 & $19.92(0.89)$ & $Z=-2.50$ & & \\
\hline Non -employees & 89 & $17.52(0.74)$ & $p<0.01$ & & \\
\hline
\end{tabular}

Occupational status/satisfaction

\section{Discussion}

The purpose of the present study aimed to give an insight into the outcomes of people who have been diagnosed with mild ID during the period of lockdown due to the COVID-19 pandemic, in terms of quality of life, anxiety, and depression. Impact of demographic variable also explored. Given the retrospective nature of the research design, the results should be interpreted with caution. Additionally, it is not possible to know if the given responses of the participants in the questionnaires reflect the effects of the pandemic, as there are no comparisons with corresponding values in the people themselves before the pandemic. Our sample seems to be able to evaluate their present life despite their cognitive deficits.

The term "quality of life" remains conceptually vague making its clarification a particularly complex affair. This concept should aim at equality and the enjoyment of human rights regardless of socioeconomic status or disabililities ${ }^{37}$.

Recently, findings suggest that the impact of COVID-19 pandemic had negatively hindered the quality of life of people with ID in the following areas: continuity and security, interaction with others, participation in the life community, intimate relationships and selection of goals ${ }^{38}$. The majority of our sample expressed a moderate level of total quality of life. Our sample report high levels in the Satisfaction subscale of the quality of life questionnaire. This expressed satisfaction is likely due to limited ambitions and probably due to lack of perspectives in their lives. These findings are in keeping with previous studies ${ }^{39,40,41}$.

According to the international literature, this phenomenon has been found with the term of "Disability Paradox". Fellinghauer et al. ${ }^{42}$ state that an unfavorable social environment leads to social constraints and reduced social participation, and the level of quality of life decreases only when these constraints are present in individual's life. A possible interpretation of the 
increasing levels of satisfaction in the quality of life measurements of people with ID is that they usually tend to compare themselves to other people with disabilities ${ }^{43}$. Based on Dunn and Brody ${ }^{44}$ healthy people often underestimate the consequences of disability or overestimate its effects.

Fabian ${ }^{45}$ argues that limited life experiences may interfere with the ability to compare quality of life assessment, while reported satisfaction may be an indication of past experiences and current expectations. Limited ambitions can lead many people to report satisfaction in current living conditions, which may be considered insufficient by social demands. For some people, with severe disabilities, many of the quality of life questionnaires are either contraindicated or impossible to complete as they aim at socially desirable goals. Although part of the literature refers to the existence of a positive correlation between functionality and quality of life, there seems to be a lack of empirical studies regarding individuals with various disabilities to confirm such a relationship ${ }^{46}$.

Quality of life measurements are mostly related to satisfaction measurements without separating the latter from individuals' perceptions of subjective well-being. Assessing the extent to which individuals are satisfied with their lives may include a cognitive character that deals with the mismatch between people's expectations and aspirations and their current state of life $\mathrm{e}^{47}$.

The findings of quality of life research, which are based on the concept of satisfaction, suggest that most people have an ability to maintain their level of satisfaction despite constant environmental changes. This means that if an individual feels dissatisfied because he or she perceives a discrepancy between his or her individual values and preferences and objective circumstances, he or she can reduce the perceived dissatisfaction by either changing his or her environmental conditions or modifying his or her values and preferences. Usually most people use both strategies with different combinations.

The use of measurements of subjective satisfaction as an indicator of quality of life, does not allow differentiating between the quality of life of people who have reduced their ambitions and are satisfied with very simple things and those who are satisfied with their lives because of achieving their desired goals. The majority of the sample (76.3\%) expressed high levels of home satisfaction, while $67.7 \%$ reported fully accepted by most of their family. The important given to people with intellectual disabilities in their contact with family, as well as the 
indication that the essential support of the family to these individuals plays an essential role in the emotional well-being of them ${ }^{48}$. According to Lunsky ${ }^{49}, 85 \%$ of adults with ID tend to stay with their parents, while close association with their family members increases the feeling of life satisfaction ${ }^{50}$. Excessive help from the family environment and the attachment of people with intellectual disabilities may create difficulties in their interpersonal relationships. These people very often maintain the image of the isolated person, clinging to people close them.

With regard to the subscale Adequacy and Productivity, the satisfaction expressed seems to be linked to monetary gains. Only a very small percentage $(11.9 \%)$ of our sample works occasionally. The majority of people with ID did not work full time and has relatively low wages $^{51}$.This finding coincides with the research of Soulis, in Greece ${ }^{52}$ where a correlation between work and financial independence in people with ID was recorded. In contrast to other studies $^{53,54}$ no similar findings were found. On the research ${ }^{30}$ participated 1264 adults with ID, a high unemployment rate occurred and only a small percentage had paid work. The concept of vocational rehabilitation seems to be related to the degree of autonomy that persons acquire ${ }^{55,56}$. If adults with ID decide for themselves and work in jobs close to their interests, then in the long run they will ensure professional identity, autonomy and financial prosperity ${ }^{57,58}$. Researches support that there is an association between being in paid employment and better physical and mental health status. In addition job satisfaction in people with ID is determined by job demand and job researches ${ }^{56}$.

However, the variable of quality of life that the individuals in our sample seemed to experience most negatively is that of empowerment and independence. Iindividuals seems to have low levels of independence. While individuals report they are satisfied with their lives, when they referred to the degree of independence and control of the exercise over their lives, most referred to their low levels of independence and high levels of dependence on others. Miller and Chan $^{59}$, claim that individuals with ID can feel satisfied with their lives, regardless of the degree of independence and autonomy. However, the overprotective attitude towards them should also be taken into account, as the lack of independence does not stem from their cognitive deficits but also from the way they deal with the environment ${ }^{60}$. In most of the cases, people with intellectual disability have the option of choosing only insignificant issues, while when it comes to important issues, others decide for them ${ }^{61}$. In addition, they describe friendships in the way others would describe a relationship with acquaintance ${ }^{49}$. A survey ${ }^{62}$ 
among adults over 40 years, two in five participants reported having no friends other than family members. According to Rogers et al. ${ }^{63}$ these people learned to rely on their parents for the rest of their lives, so they are often manipulated by them and become irresponsible and passive.

Regarding to Social inclusion/Integration recorded a low level of Quality of life and they report that they feel anxious with what they are asked (51.1\%). This anxiety can probably be caused by the existence of a stressful and pressing support ${ }^{49}$. Leisure activities are usually spent in watching TV and playing games in the computer. Social restrictions, due COVID-19, have negatively impacted social conclusion and reported high use of technology ${ }^{64}$. People take part in various social events, they do not have a close relationship with neighbors, but they are happy with the way they are treated. Social inclusion and participation in leisure activities increase with greater functional independence and positive community attitudes ${ }^{65}$. They need extra support to participate successfully in public area. Probably, exaggerate the concept of friendship and perceive the friendly mood as a sign of friendship ${ }^{66}$ while the majority of friends are peers with ID $^{67}$. These people participate less in recreational programs. Friendship predict improved outcomes in almost every area of one' s life; as such it is critical to promote the development, maintenance and growth of friendship of people with ID $^{68}$. Research suggests that although people with ID refer that they have friends, were unsatisfied with the number of them and the amount of contact. Social inclusion is supported by: creating opportunities to communicate their interests and desires, providing opportunities to choose self- directed activities, selecting, encouraging, and placing objects to support interactions between them ${ }^{69}$.

Investigating the relationship between demographic variables and quality of life, significant gender differences only in the subscale satisfaction was found. More specific, satisfaction was the most preserved domain by men and the most educated, while employees expressed also more satisfaction than non-employees. No statistical significant differences were found between total quality of life and gender. Kaliaca et al. ${ }^{39}$ did not find significant differences between dimensions of quality of life for males and females. The view that gender does not affect the total quality of life is supported by several researches ${ }^{30,34}$. When a total quality of life is not observed, it is probably not due to the individuals themselves, but to the inability of society to understand these persons as an autonomous being. 
In the evaluation of anxiety and depression, marginally increased rates of anxiety and depressive symptoms are recorded. A percentage of $36 \%$ show mild depressive symptoms ranging from mild to moderate depression (BDI> 10), while the majority of the sample experiences stress as a condition rather than a personality trait. Naturally, we are not able to know if the described levels of depression and anxiety are the result of isolation due the pandemic, or their life situation or a combination of all factors.

Research in Poland ${ }^{70}$ on which participated individuals with developmental disabilities showed mild or more severe symptoms of anxiety and depression and females were more affected than males. Research in Germany ${ }^{71}$ found that children and adolescents felt significantly burdened by lockdown, social distancing and homeschooling measures. In addition, they experienced lower quality of life, and more mental problems, especially hyperactivity and peer problems. Depression, anxiety and insomnia were highly prevalent among individuals with a disability during COVID-1972.

\section{Limitations}

This research has some limitations. Some of these are the followings:

1) The research design that was applied had the logic of the mainly relational approach without looking for cause-effect relationships. Therefore our findings cannot be generalized as they are an indication that needs further systematic investigation and confirmation.

2) Systematic evaluation of quality of life requires a longitudinal approach. Our research based on the perceptions of individuals during isolation.

3) Previous perceptions of quality of life, anxiety, and depression were not evaluated

4) Meanings of people about quality of life, anxiety and depression based on their declarations and because of cognitive deficits it could be inaccurate.

5) Quality of life measurements were based on the principle of satisfaction. Other parameters may be included in quality of life assessments besides that. 


\section{Acknowledgements}

The authors would like to thank the individuals and their parents for the participation in this study.

\section{References}

[1] Venkatesh A. Social distancing in covid-19: What are the mental health implications? $B M J, 2020 ; 369$ doi:https://doi.org/10.1136/bmj.m1379(published 06 April 2020).

[2] Yingfei,Z ,Zheng,M. Impact of COVID-19 Pandemic on mental health and quality of life among local residents in Liaoning Province, China: A cross-sectional study. International Journal Research Public Health,2020; 17(7),2381.

[3] Galea,S,Merchant,R,Lurie,N. The mental health consequences of covid-19 and physical distancing: The need for prevention and early intervention.2020; JAMA, Intern Med doi: 10.1001/jamainternmed.2020.1562.

[4] Pfefferbaum, B, \& North, CS. Mental Health and the Covid - 19 Pandemic. The New England Journal of Medicine,2020; 383 (6), 510 - 512. doi: 10.1056/NEJMp2008017.

[5] Coutenay, K, \& Perera, B. COVID - 19 and people with intellectual disability: impacts of a pandemic. Irish Journal of Psychological Medicine,2020; 1 - 6. doi: $10.1017 / \mathrm{ipm} / 2020.45$.

[6] Claes,C,van Hove,G,Vandevelde,S, van Loon,J, \&Schalock,RL. The influence of supports strategies,environmental factors, and client characteristics on quality of life-related personal outcomes. Research in Developmental Disabilities, 2012; 33(1),96-103.

[7] Reindres,H,\&Schalock,RL. How organizations can enhance the quality of life of their clients and assess their results. The concept of quality of life enhancement. Journal of Intellectual and Development Disabilities,2014;119,291-302.

[8] Gomez,L E,Verdugo,MA, Arias,B,Navas,P,\&Schalock,RL. The development and use of provider profiles at the organizational and systems level. Evaluation and Program Planning,2013;40,17-26.

[9] Liu, B. Quality of life Indicators in U.S. Metropolitan Areas: A Statistical Analysis, N.Y.:1976; Praeger. 
[10] Wallander,J,Koot,H. Quality of life in children: A critical examination of concepts, approaches, issues, and future directions. Clinical Psychology Review,2016; http://dx.doi.org/10.106/i.cpr.2015.11.007.

[11] Cammins, RA, Li,N, Wooden,M,\& Stokes,M. A demonstration of set -points for subjective wellbeing. Journal of Happiness Study,2014; 15,183-206.

[12] Ruggeri, M, Nose, M, Bonetto, C, et al. Changes and predictors of change in objective and subjective quality of life: Multiwave follow-up study in community psychiatric practice. The British Journal of Psychiatry, 2005;187(2), pp.121-130.

[13] Shalock,R,Bonham,G,Marchand,C. Consumer based quality of life assessment: a path model of perceived satisfaction. Evaluation and Program Planning,2000; 23,77-87.

[14] Razik K. \& Beecham J. Review of Factors Important in Use of Survey Data for Quality and Performance Improvement. QORU Discussion Paper. Quality and Outcomes of person-centered care policy Research Unit (QORU), 2014; Canterbury.

[15] World Health Organization WHOQOL: Study Protocol: Division of Mental Health. 1993; Geneva: World Health Organization.

[16] De Kroon, M,Hodiamot,P. Meten van Kwaliteit van Leven in kinderpsychiatrie. Tijdschrift voor psychiatrie,2008; 50(11) 725-734.

[17] Shalock,R,Verdugo,M,Gomez,L,Reinders,H. Moving us Toward a Theory of Individual Quality of Life. American Journal of Intellectual and Developmental Disability,2016; 121(1);1-12.

[18] Barry, MM \& Crosby,C. Quality of life as en evaluative measure in assessing the impact of community care on people with long-term psychiatric disorders, British Journal of Psychiatry, 1996;168, 210-216.

[19] Verdugo,M,Shalock,R,Keith,K,Stancliffe,R. Quality of Life and its Measurement :Important Principles and Guidelines. Journal of Intellectual Disability Research,2005; 49(10)707-717.

[20] Reindres,H,\&Schalock,RL. How organizations can enhance the quality of life of their clients and assess their results. The concept of quality of life enhancement. Journal of Intellectual and Development Disabilities,2014; 119,291-302.

[21] Brown, I, Hatton,C,\&Emerson,E. Quality of life indicators for individuals with intellectual disabilities: Extending current practice. Intellectual and Developmental Disabilities,2013; 51,316-332. 
[22] Hamming,JF,De Vries. Measuring quality of life. British Journal of Surgery,2007; 94:923-924.

[23] Testa,MA,Simonson,DC. Assessment of quality of life outcomes. Current Concepts.1996; $334: 835-840$.

[24] Simões',C,Santos,S. Comparing the quality of life of adults with and without intellectual disability. Journal of Intellectual \&Developmental Disability.2016; Vol. 60(4), 378-388

[25] Stöppler,R. Einführung in die Pädagogik bei geistiger Behinderung. München: 2017; Ernst Reinhardt Verlag

[26] Albrecht,GL, Seelman,KD\&Bury,M. An Institutional History of Disability. In G.L. Albrecht,K.D.,Seelman\&M.Bury,(Ed.), Handbook of Disability Studies 2001;(pp.1168).Thousand Oaks, London: Sage Publications

[27] Cluley,V.(2017).From Learning disability to intellectual disability- Perceptions of the increasing use of the term "intellectual disability" in learning disability policy, research and practice.2017; British Journal of Learning Disabilities, https://doi.org/10.1111/bld.12209

[28] Schalock,RL,Gardner,JF,\&Bradley,VJ. Quality of life for people with intellectual and other developmental disabilities. 2017;AAIDD.

[29] Shalock,RL,Borthwick-Duffy,SA,Bradley,VJ et al. Intellectual disability: Diagnosis, classification and systems of supports. 2010;(11 ${ }^{\text {th }}$ ed.). Washington,DC: American Association on Intellectual and Developmental Disabilities

[30] Simões' C,Santos,S. Understanding the gaps among citizens with and without intellectual disability: the role of the quality of life paradigm. 2019; workjournal, International Congress of Health and Well- being Intervention.

[31] Wilson,KS, Wiersma,LD, \&Rubin,DA. Quality of life in children with Prader Willi syndrome: Parent and child reports. Research in Developmental Disabilities,2016; 57(1), $149-157$

[32] Hensel,E,Rose,J,Stenfert Kroese,B,\&Banks-Smith. Subjective judgments of quality of life: A comparison study between people with intellectual disability and those without disability. Journal of Intellectual Disability Research, 2002;46(2),95-107.

[33] Ribeiro, J,Silva, T,Varela,C. Quality of life of people with DID with significant support needs: A comparative study with non DID pairs. Research and Networks in Health,2017; $3(1), 1-11$. 
[34] Schalock,RL,Keith,KD. Quality of Life Questionnaire Manual.1993; IDS Publishing Corporation.

[35] Beck,AT,Steer,RA,\&Brown,GK. Manual for the Beck Depression Inventory.1996; San Antonio,TX: Psychological Corporation.

[36] Spielberger, CD. State-trait Anxiety Inventory: A Comprehensive Bibliography. $2^{\text {nd }}$ edn. Palo Alto,1989; CA: Consulting Psychologists Press.

[37] Verdugo,MA,Navas,P,Gomez,L,Shalock,RL. The concept of quality of life and it's role in enhancing human rights in the field of intellectual disability. Journal of Intellectual Disability Research.2012; 56,(11), 1036-1045.

[38] Fridman,C. The COVID-19 pandemic and quality of life outcomes of people with intellectual and developmental disabilities. Disability and Health Journal,2021; Vol 14(4), https://doi.org/10.1016/i.dhjo.2021.101117.

[39] Kaljača,S,Dučić,B,Dordić,S. Quality of life in adults with intellectual disabilitiesObjective Indicators. Speciljalna edukacija i rehabilitacia 2018; doi: 364-787-053.8056.313 .

[40] van Asselt-Goverts,AE,Embregts,PJC,\&Hendricks,AHC. Social networks of people with mild intellectual disabilities: Characteristics, satisfaction, wishes and quality of life. Journal of Intellectual Disability Research,2015; 59(5), 450-461.doi 10.1111/jir.12143.

[41] Hoppe,S. Chronic Illness as a source of Happiness. Paradox or perfectly normal? Health, Culture and Society, 2013; Vol5 (1) 265-278.

[42] Fellinghauer,B,Reinhardt,JD,Stucki, G, et al. Explaining the disability paradox: A crosssectional analysis of the Swiss general population. BMC Public Health,2012; 12(1),655664.

[43] Ubel, PA,Loewenstein,G,Schwarz,N,\&Smith,D. Misimagining the unimaginable The disability paradox and health care decision making. Health Psychology, 2005;24(4),557562.

[44] Dumn,DS, \&Brody,C. Defining the good life following acquired physical disability. Rehabilitation Psychology, 2008; 53(4),413-425.

[45] Fabian, E. Using quality of life indicators in Rehabilitation Program Evaluation, Rehabilitation Counseling Bulletin, 1991; 34, 344-356.

[46] Cheng, Sheung-Tak. Subjective quality of life in the planning and evaluation of programs, Evaluation and Program Planning, 1988; 11, 123-134. 
[47] Michalos,AC. Satisfaction and happiness, Social Indicators Research,1980; 8: 385- 422.

[48] Bramston,P,Chipuer,H,\&Pretty,G. Conceptual principles of quality of life: an empirical exploration. Journal of Intellectual Disability Research,2005; 49(10) 728-733.

[49] Lunsky, Y. Individual Differences in Interpersonal Relationships for Persons with Mental Retardation. Dept. of Psychiatry, University of Toronto, 2006; Toronto, Ontario, Canada.

[50] Cummins, RA., Law, ALD. Personal Well-Being Index-School Children 2005; (PWI-SC).

[51] Bouck,EC. Secondary students with moderate/severe intellectual disability: Considerations of curriculum and post-school outcomes from the National Longitudinal Transition Study. Journal of Intellectual Disability Research,2012; 56(12),1175-1186.

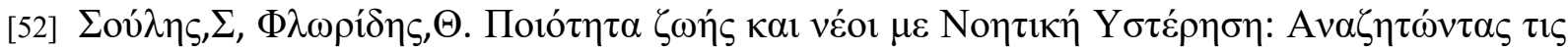

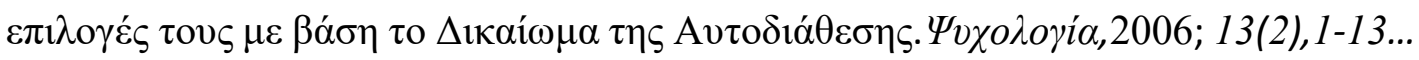

[53] Forte,M,Jahoda,A,\&Dagnan,D. An Anxious time? Exploring the nature of worries experienced by young people with mild to moderate intellectual disability as they make the tansition to adulthood. British Journal of Clinical Psychology,2011; 50,398-411.

[54] Miller,SM,\&Chan,F. Predictors of life satisfaction in individuals with intellectual disabilities. Journal of Intellectual Disability Research,2008; 52(12),1039-1047.

[55] Ali,M, Schur,L,\& Blank,P. What types of jobs do people with disabilities want?.Journal of Occupational Rehabilitation, 2011; 21(2), 199-210.

[56] Flores,N,Moret-Tatay,Bermejo,B,Vazquez,A,Jenaro,C.Assessment of Occupational Health and Job Satisfaction in Workers with Intellectual Disability: A Job DemandsResources Perspective. Int. J. Environ. Res. Public Health2021; (18),4, 2072, https://doi.org/10.3390/ijerph18042072.

[57] Carter, WE,Brock,EM,Trainor,AA. Transition Assessment and Planning for Youth With Severe Intellectual and Developmental Disabilities. The Journal of Special Education, 2014; 47(4), 245-255.

[58] Ellem,K, O'Connor,M, Wilson,J, Williams,S. Social work with marginalized people who have a mild or borderline intellectual disability: Practicing Gentleness and Encouraging Hope. Australian Social Work, 2013; Vol.66, (1), 56-71.

[59] Miller,SM,\&Chan,F. Predictors of life satisfaction in individuals with intellectual disabilities. Journal of Intellectual Disability Research,2008; 52(12),1039-1047 
[60] Strnadová ,I Evans, D. Subjective quality of life of women with intellectual disabilities: the role of perceived control over their own life in self-determined behavior. J.App.Research of Intelelctual Disability,2012; 25(1), 71-79.

[61] Wehmeyer, LM. Self-Determination and Mental Retardation in International Review of Research in Mental Retardation. 2001; Vol 24. ISBN 9780080544281

[62] McCausland, D,McCallion, $\mathrm{P}, \mathrm{Brennan}, \mathrm{D}, \mathrm{McV}$ arron, $\mathrm{M}$. Interpersonal relationships of older adults with an intellectual disability in Ireland. JARID, 2017; https://doi.org/10.1111/jar.12352.

[63] Rogers,NB,Hawkins,BA,\&Eklund,SJ. The nature of leisure in the lives of older adults with intellectual disability. Journal of Intellectual Disability Research, 1998; 42(2), 122130.

[64] McCausland,D,McCallion, P,Luus,R,Murphy,E. The impact of COVID-19 on the social inclusion of older adults with an intellectual disability during the first wave of the pandemic in Ireland. Journal of Intellectual Disability Research, 2021; 65(10), http://dx.doi.org/10.1111/jir.12862.

[65] Merrels,J, Buchanan,A,Waters,R. The experience of social inclusion for people with Intellectual disability within community recreational programs: A systematic review. Journal of Intellectual and Developmental Disability, 2017; https://doi.org/10.3109/13668250.2017.1283684.

[66] Clegg,JA.,Standen,PJ. Friendship among adults who have developmental disabilities. American Journal of Mental Retardation, 1991; 95(6), 663-671.

[67] Causland,D, McCallion, P, Carrol, R, McCarron, M. The nature and quality of friendships for older adults with an intellectual disability in Ireland. Journal of Intellectual Disability Research,2020; https://doi.org/10.1111/jar.12851.

[68] Friedman,C,Rizzolo,C. Friendship, Quality of Life and People with Intellectual and Developmental Disabilities. Journal of Developmental and Physical Disabilities,2018; 30, $39-54$.

[69] Edwards,B,Cameron,D,King, G,McPherson,A. Contextual strategies to support social inclusion for children with or without disabilities in recreation. Disability and Rehabilitation, 2021; Vol 43 (11), 1615-1625. 
[70] Gacek,M,Krzywoszanski,L. Symptoms of Anxiety and Depression in Students with Developmental during COVID-19 Lockdown in Poland. Front Psychiatry, 2021; https://doi.org/10.3389/fpsyt.2021.576867.

[71] Sieberer, U,Kaman,A,Erhart,M,Devine,J,Schlack,R,Otto,C. Impact of the COVID-19 pandemic on the quality of life and mental health in children and adolescents in Germany. European Child and Adolescent Psychiatry,2021; https://doi.org/10.1007/s00787-021$\underline{01726-5}$.

[72] Necho,M,Birkie,M,Gelaye,H,et al. Depression, anxiety symptoms, Insomnia and coping during the COVID-19 pandemic period among individuals living with disabilities in Ethiopia. Plos One 2020; https://doi.org/10.1371/journal.pone.0244530. 